The University of Maine

DigitalCommons@UMaine

Miscellaneous Publications

Publications

4-1-2016

\title{
Sedimentation Patterns in the Damariscotta River Estuary
}

Emily Chandler

University of Maine

Joseph Kelley

University of Maine

Daniel Belknap

University of Maine

Follow this and additional works at: https://digitalcommons.library.umaine.edu/ari_miscpubs Part of the Aquaculture and Fisheries Commons

\section{Repository Citation}

Chandler, Emily; Kelley, Joseph; and Belknap, Daniel, "Sedimentation Patterns in the Damariscotta River Estuary" (2016).

Miscellaneous Publications. 3.

https://digitalcommons.library.umaine.edu/ari_miscpubs/3

This Presentation is brought to you for free and open access by DigitalCommons@UMaine. It has been accepted for inclusion in Miscellaneous Publications by an authorized administrator of DigitalCommons@UMaine. For more information, please contact

um.library.technical.services@maine.edu. 


\section{MAINE}

Sedimentation Patterns in the Damariscotta River Estuary

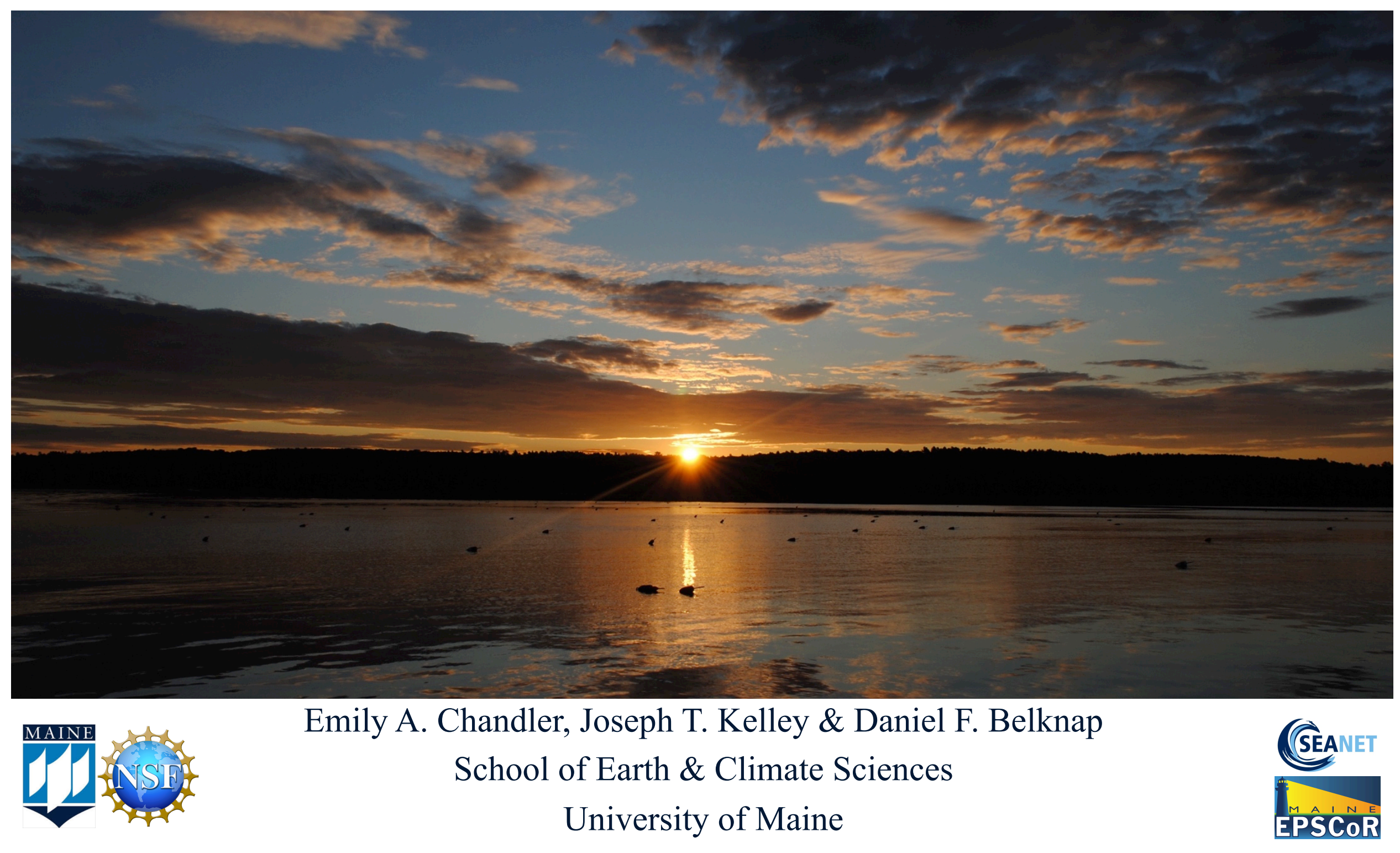




\section{MAINE}

\section{Damariscotta River Estuary}
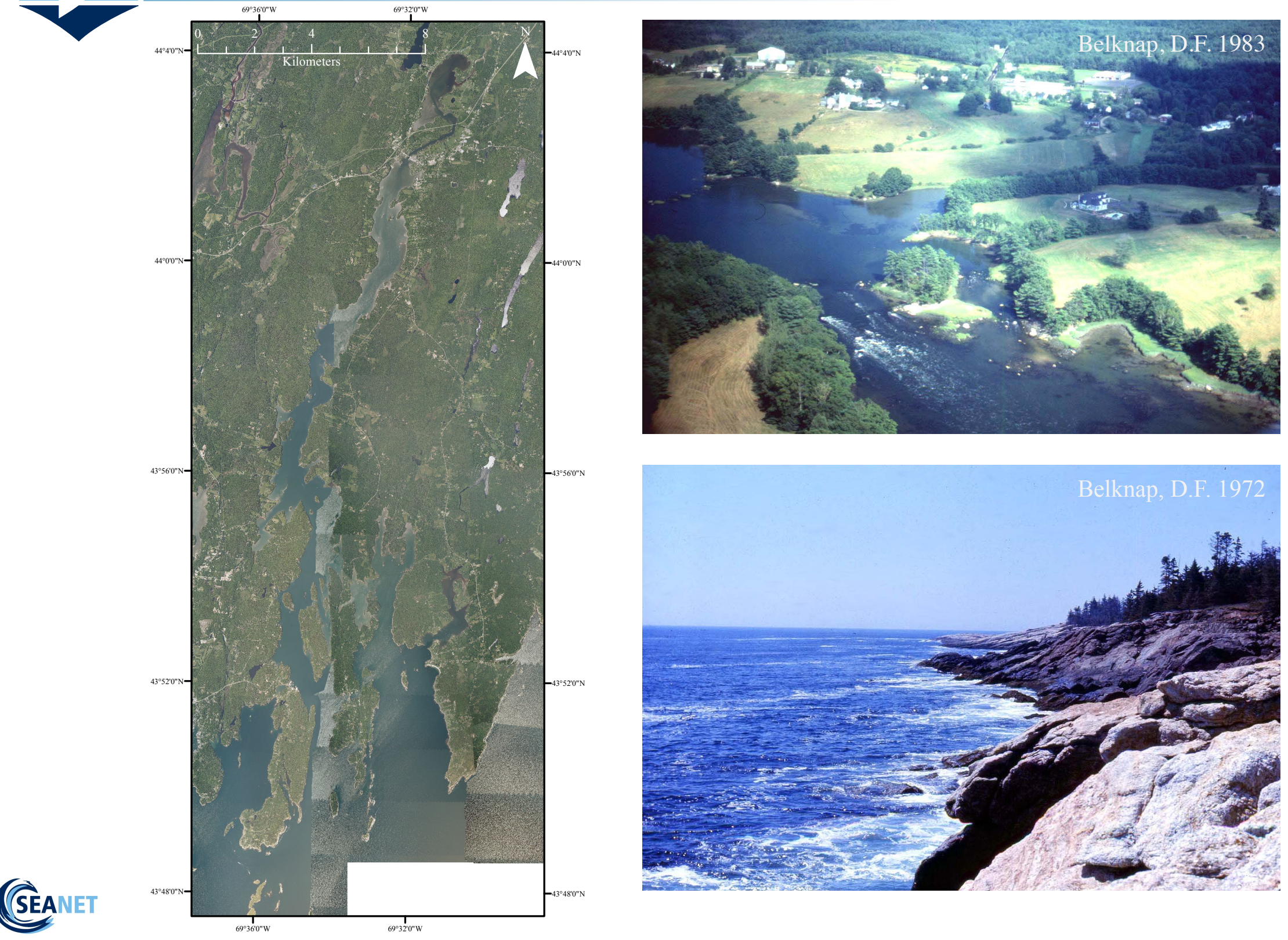


\section{Present Study}

- High Resolution Bathymetry.

- Characterize sediment \& sediment distribution throughout estuary.

- Assess temporal \& spatial trends in sediment accumulation.

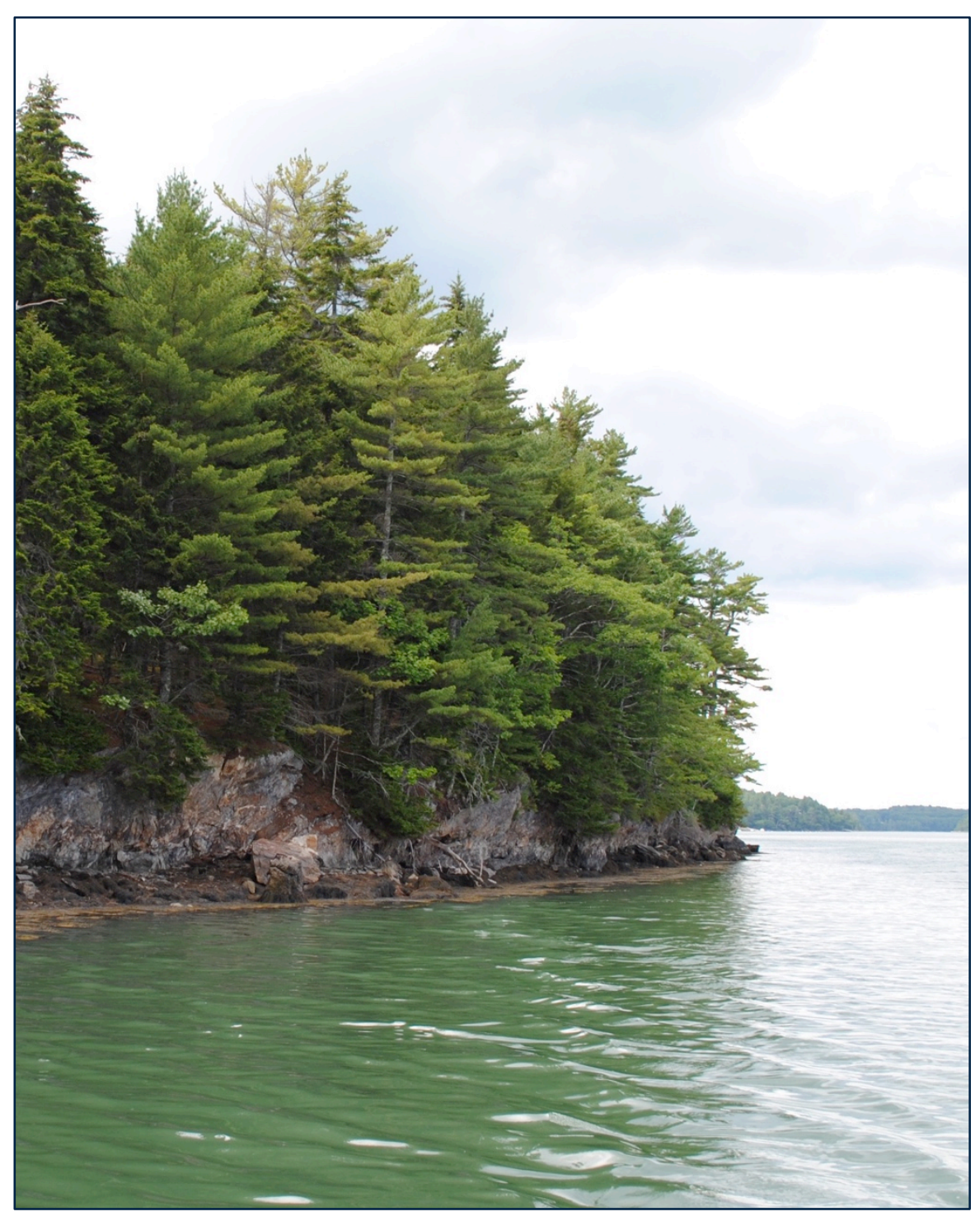




\section{MAINE}

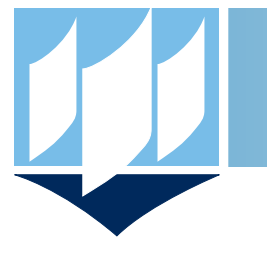

\section{Multibeam Bathymetry}
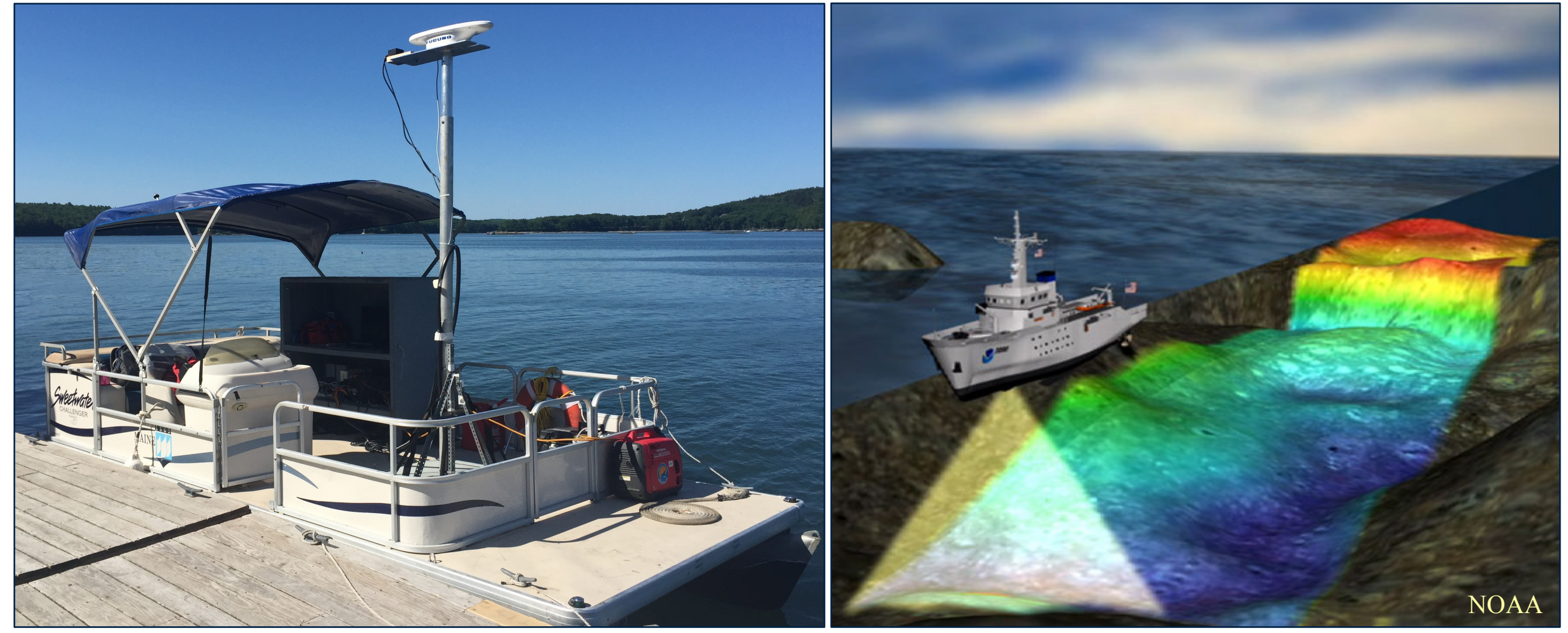

Coupled WASSP/Olex System

Resolution: $23 \mathrm{~cm}^{2}=9$ inches ${ }^{2}$

Swath width $=\sim 2 \mathrm{x}$ depth

(SEANET 


\section{MAINE \\ Mapping Extent}

- Area $=14.12 \mathrm{~km}^{2}$

- $\quad$ Volume $=1.24 \times 10^{8} \mathrm{~m}^{3}$

- Max Depth: $38.9 \mathrm{~m}=128 \mathrm{ft}$

- Time: 27 days (June, July 2015)

- Tide Correction: Pemaquid Harbor

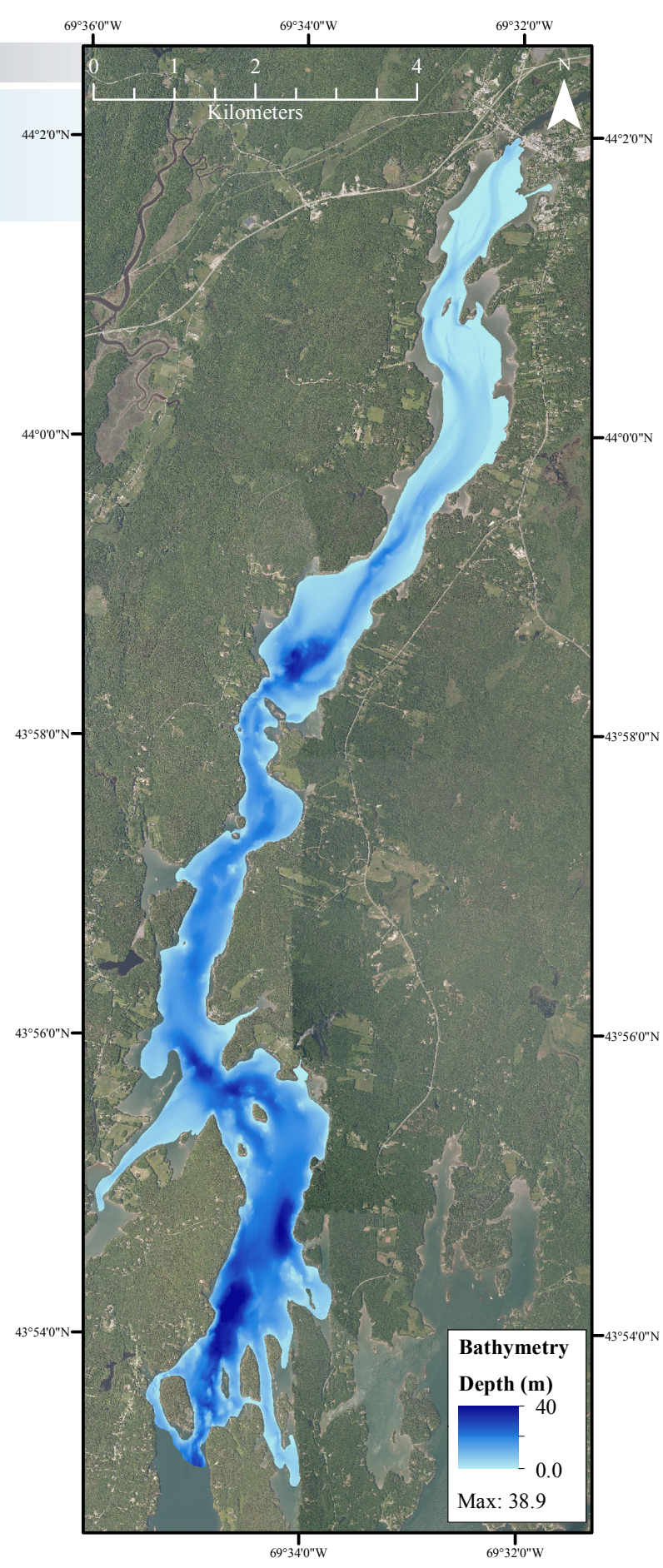




\section{MAINE}

\section{Damariscotta River Hypsometry}
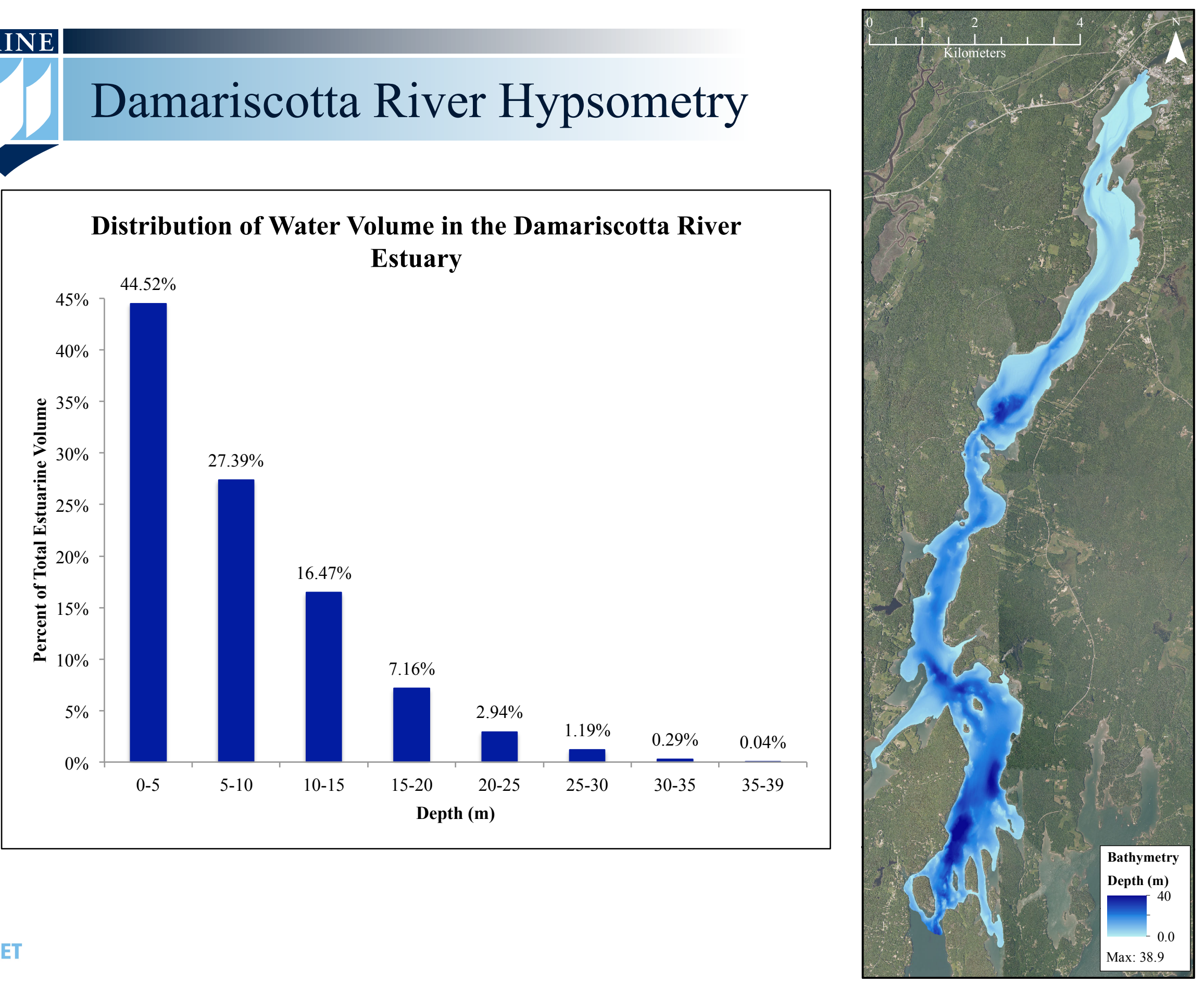


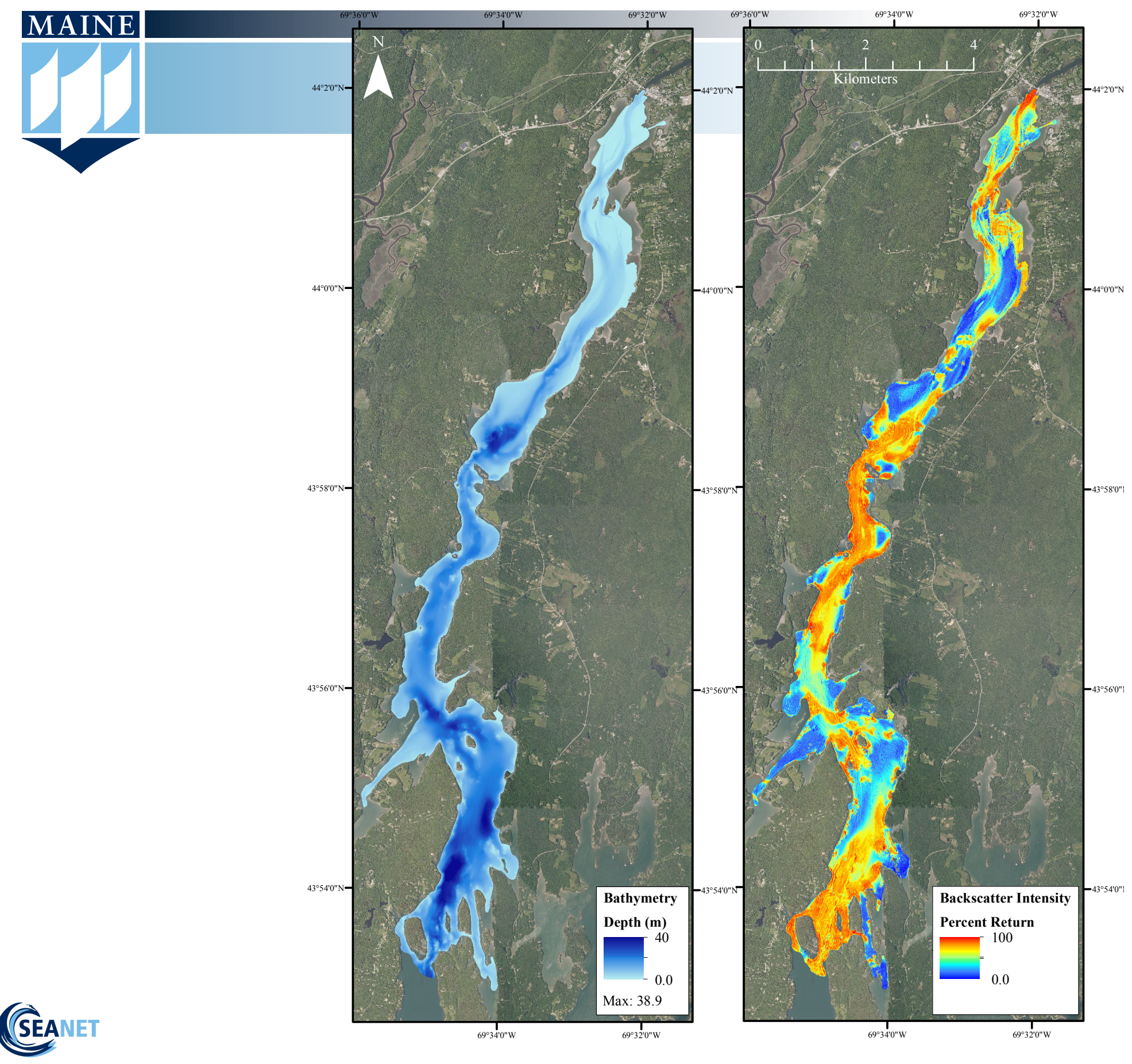




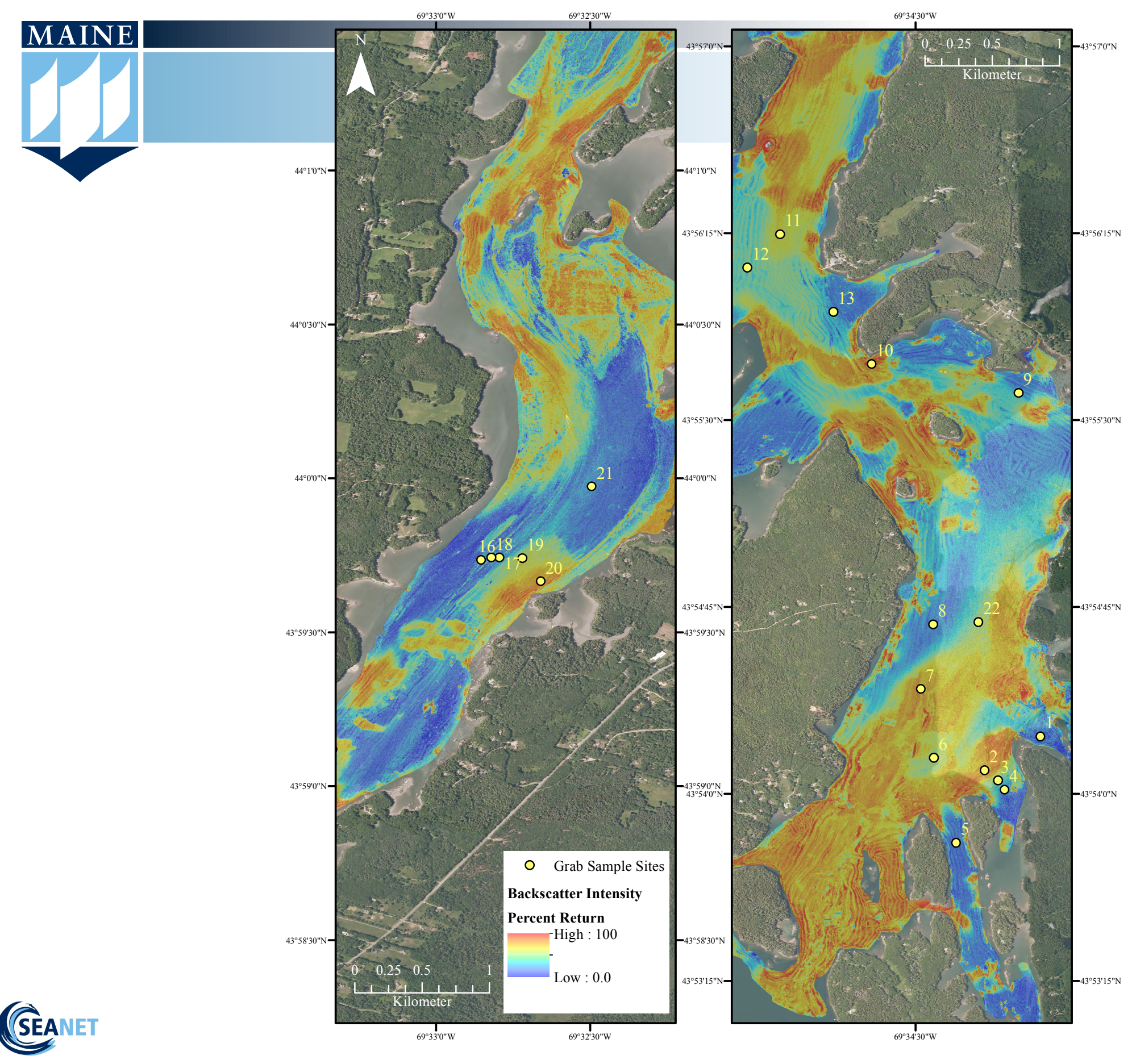




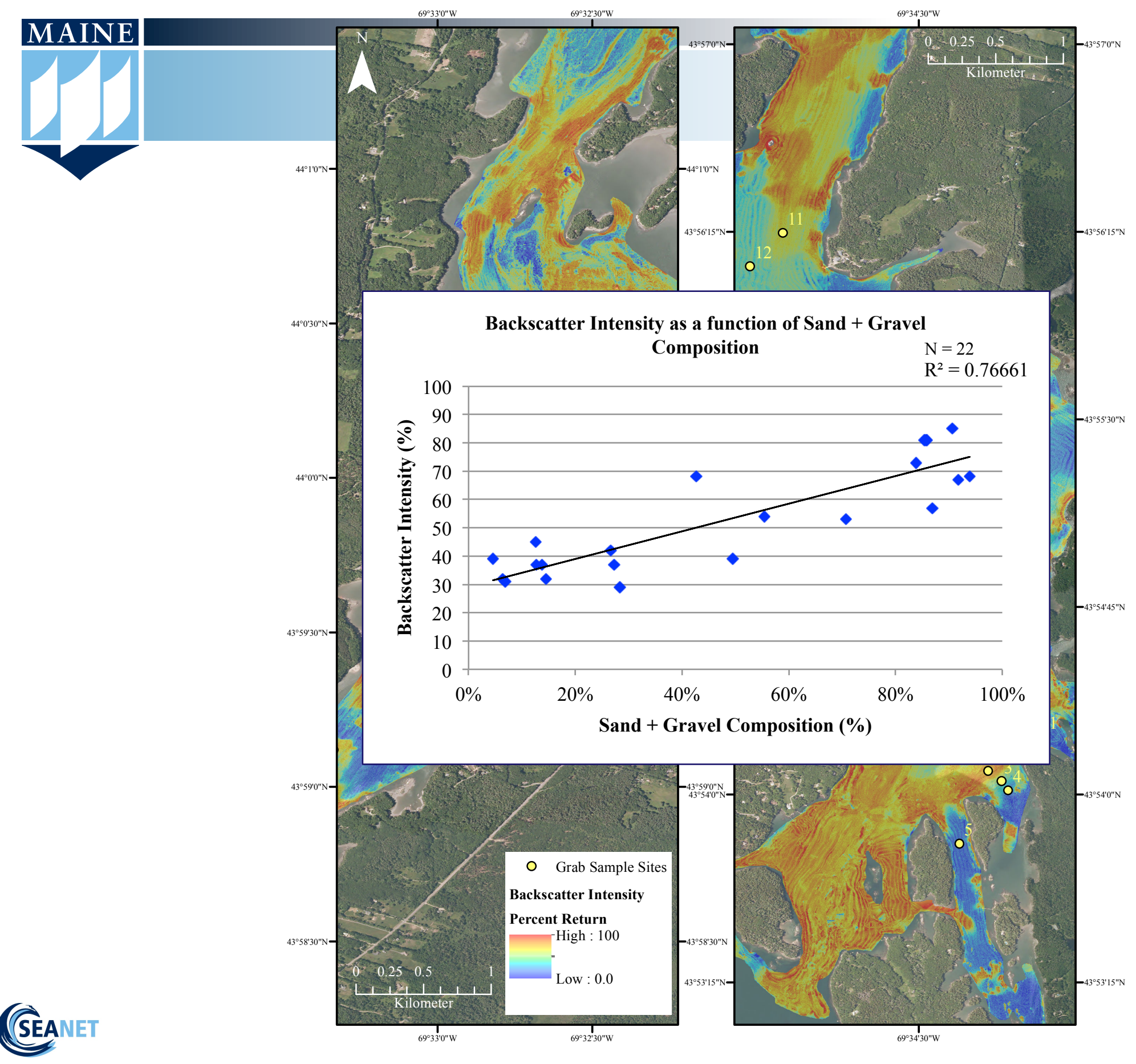




\section{MAINE}

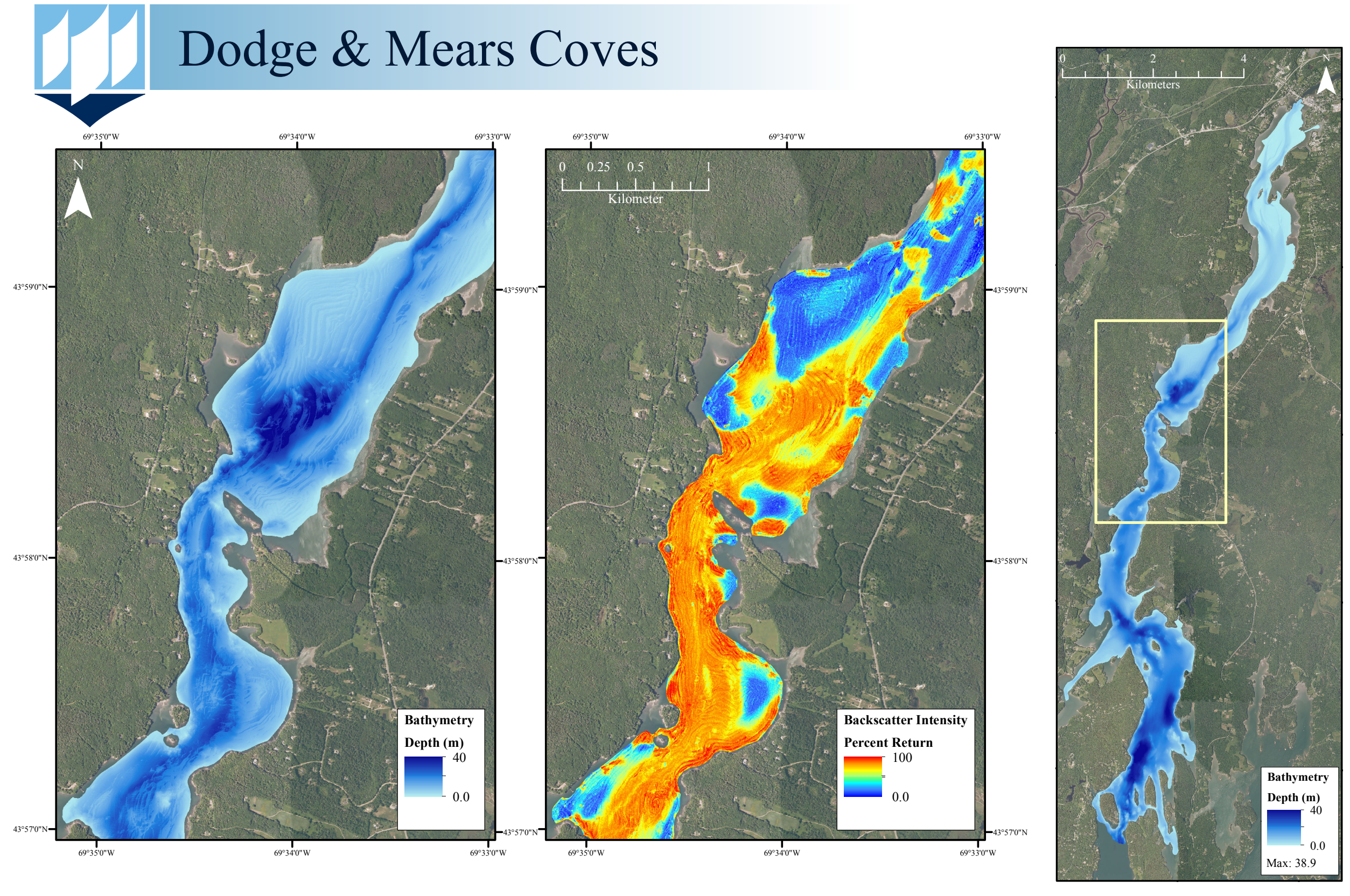

SEANET 


\section{MAINE}
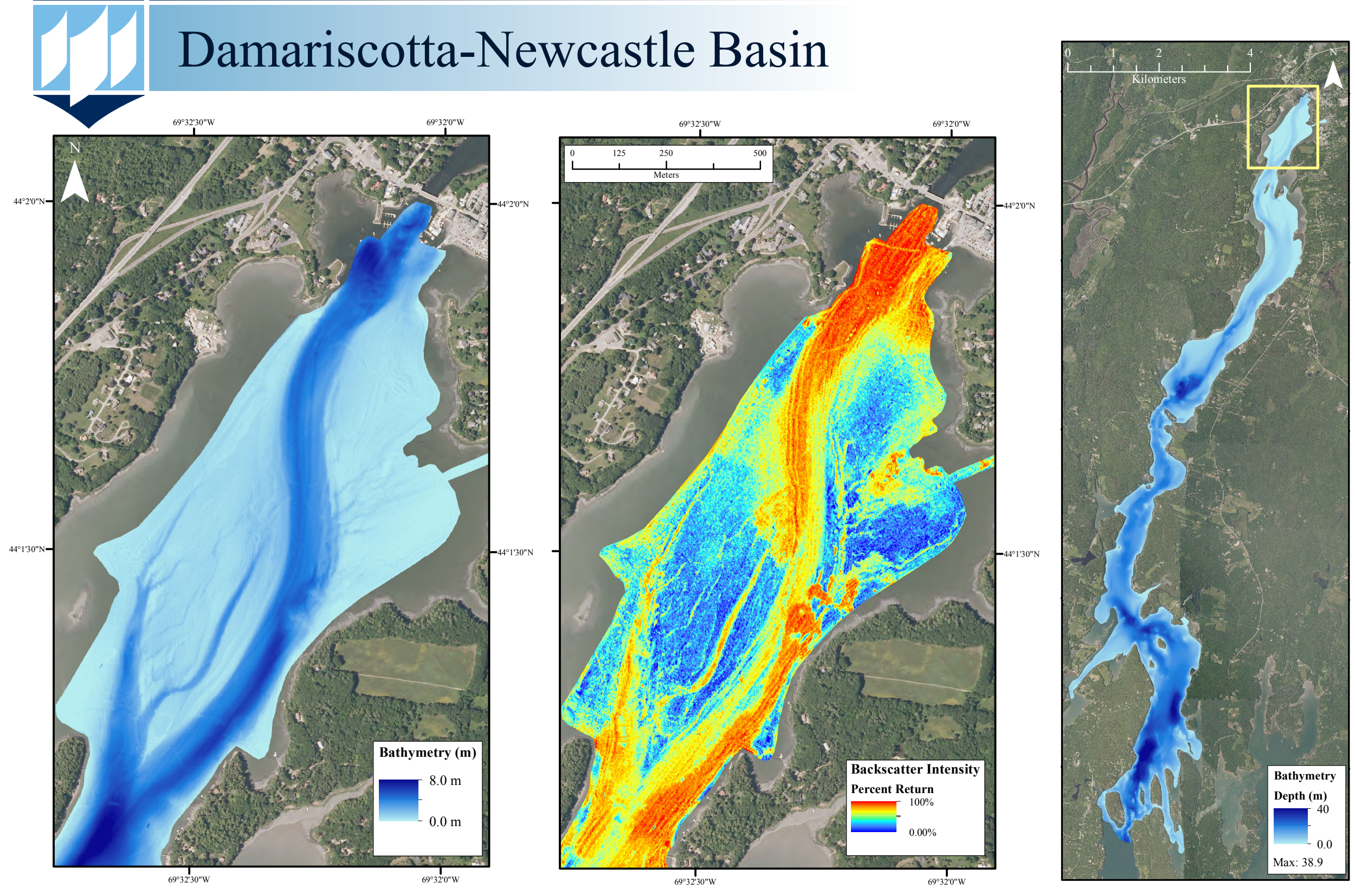

SEANET 


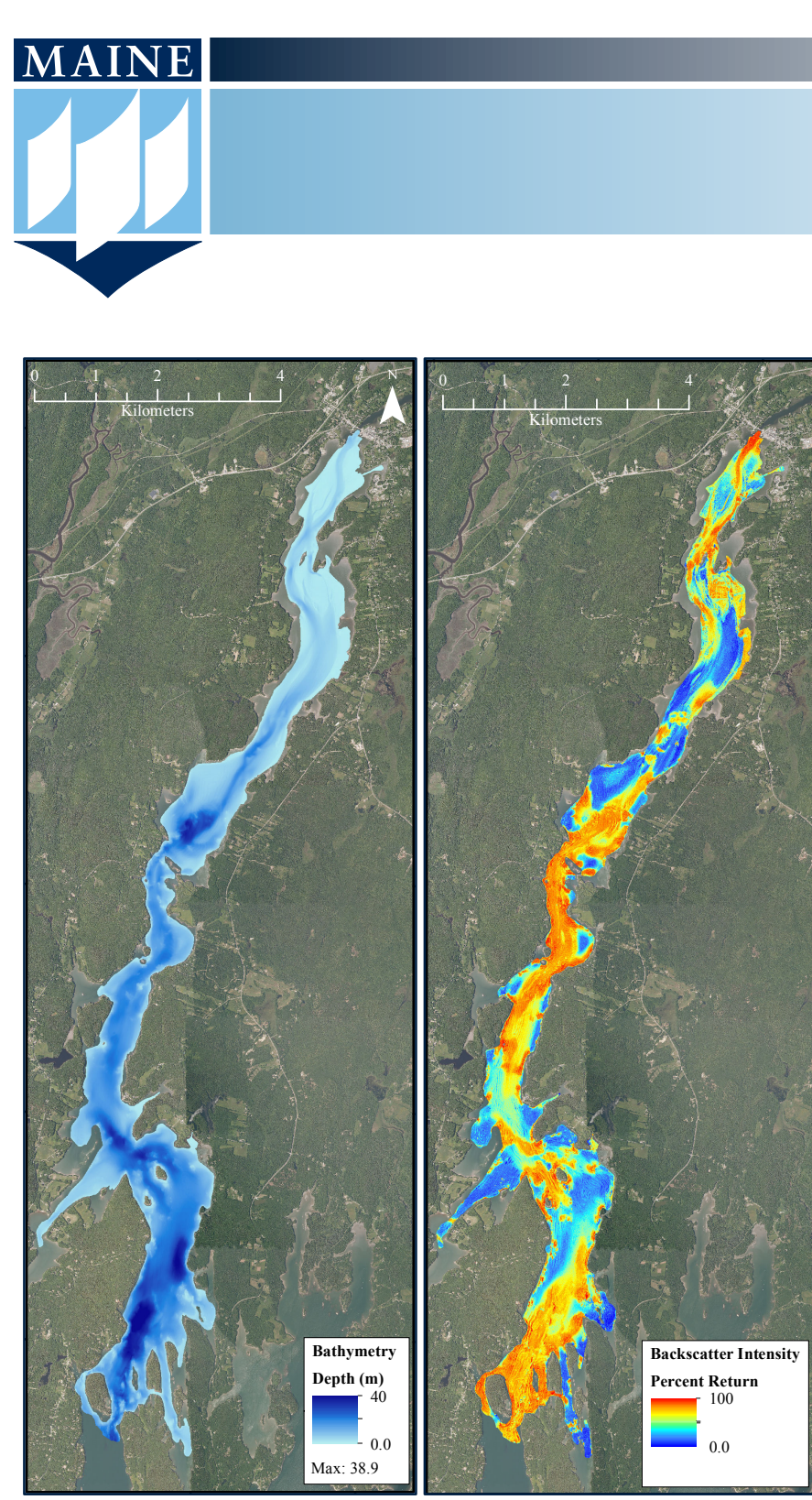

SEANET

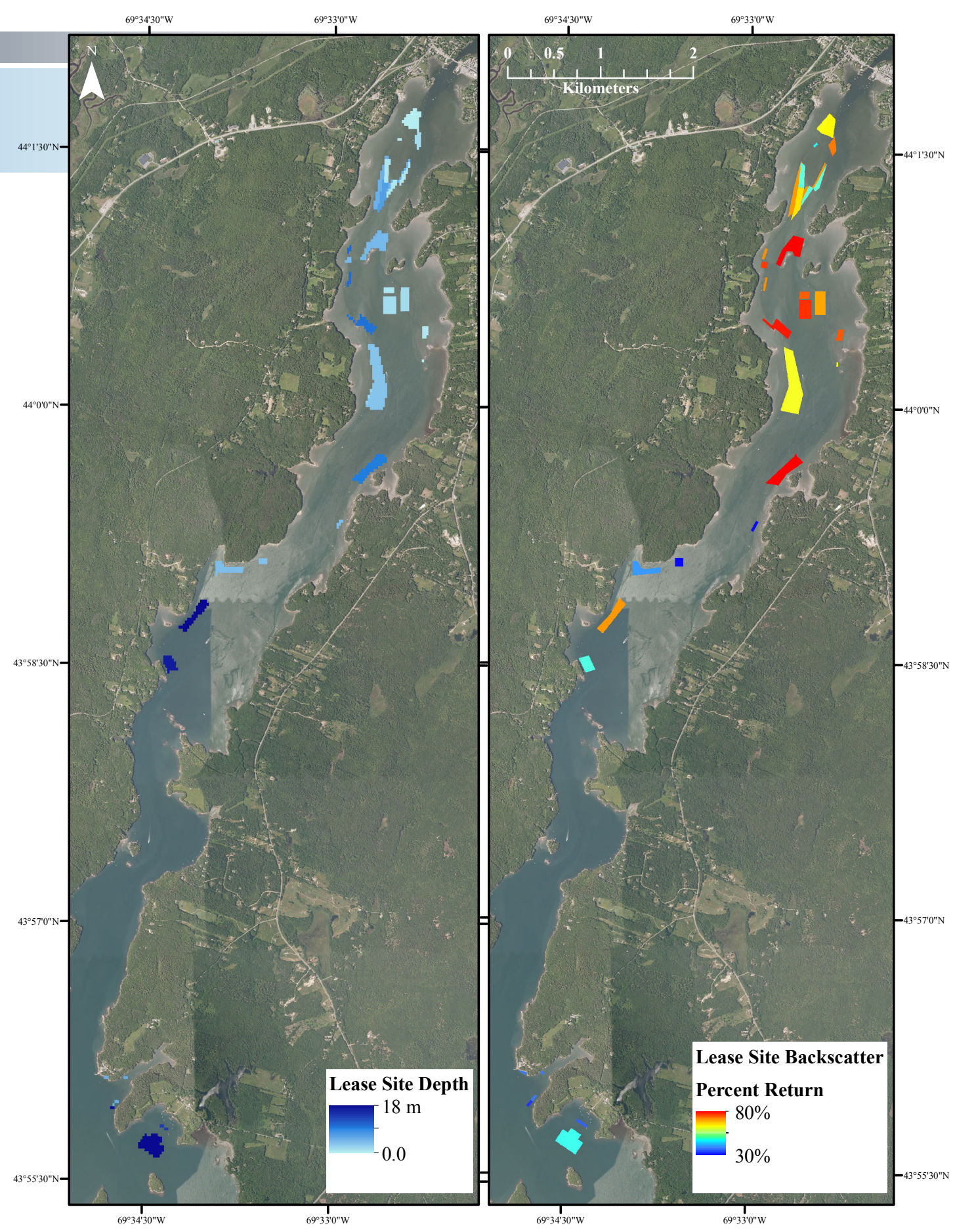




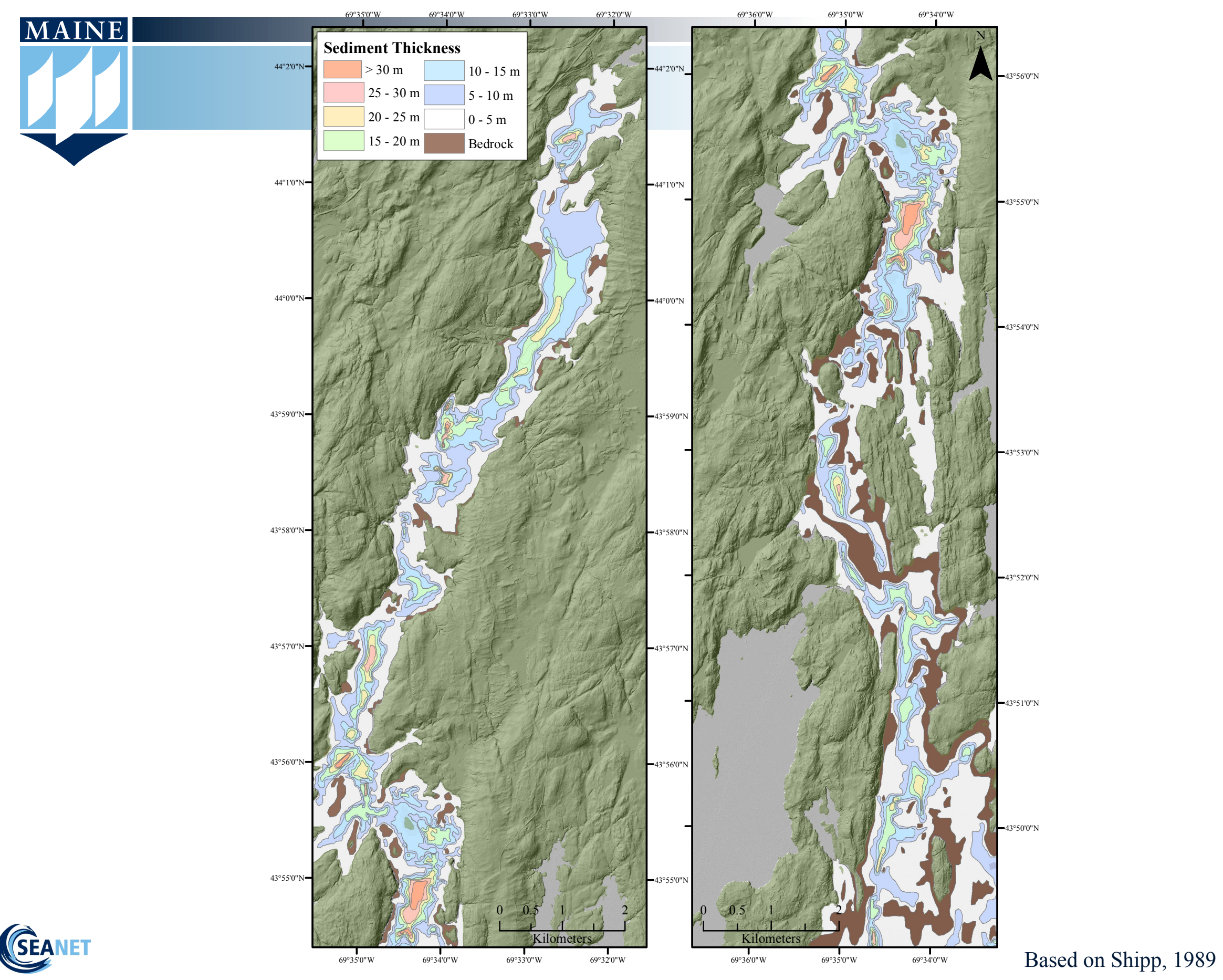




\section{MAINE}
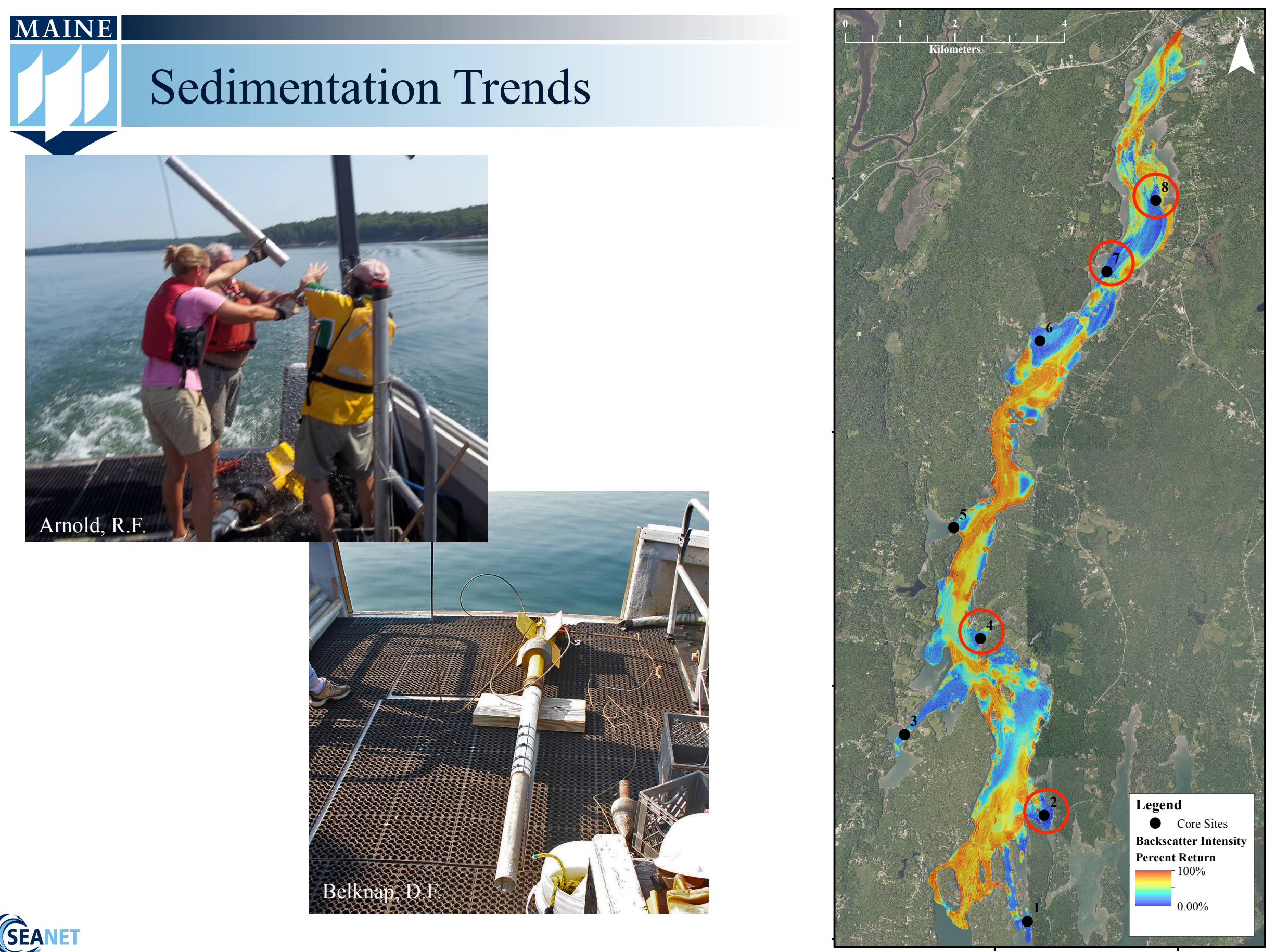

SEANET 


\section{MAINE}

\section{Historic Shipyard Sites}

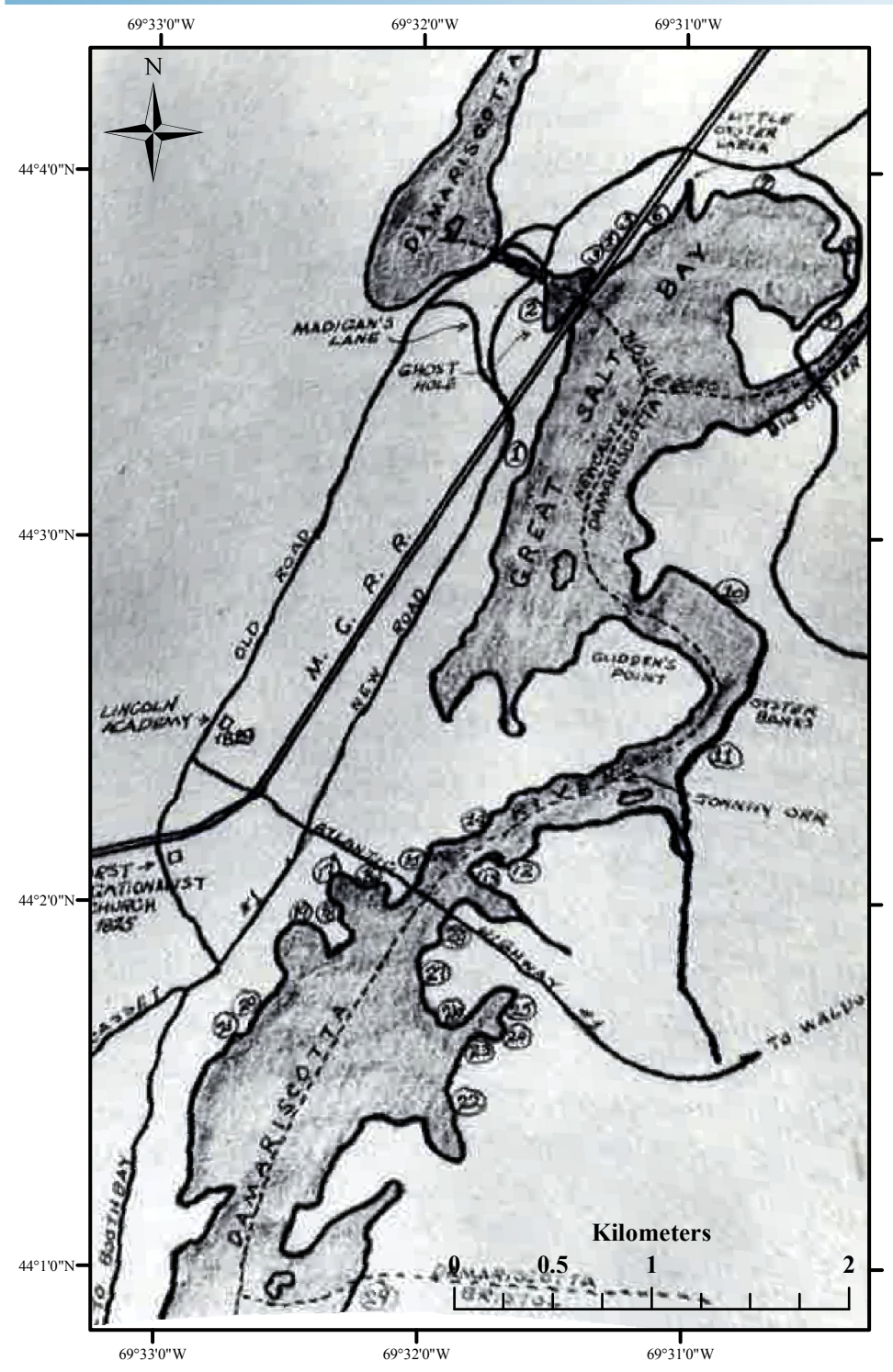

SEANET

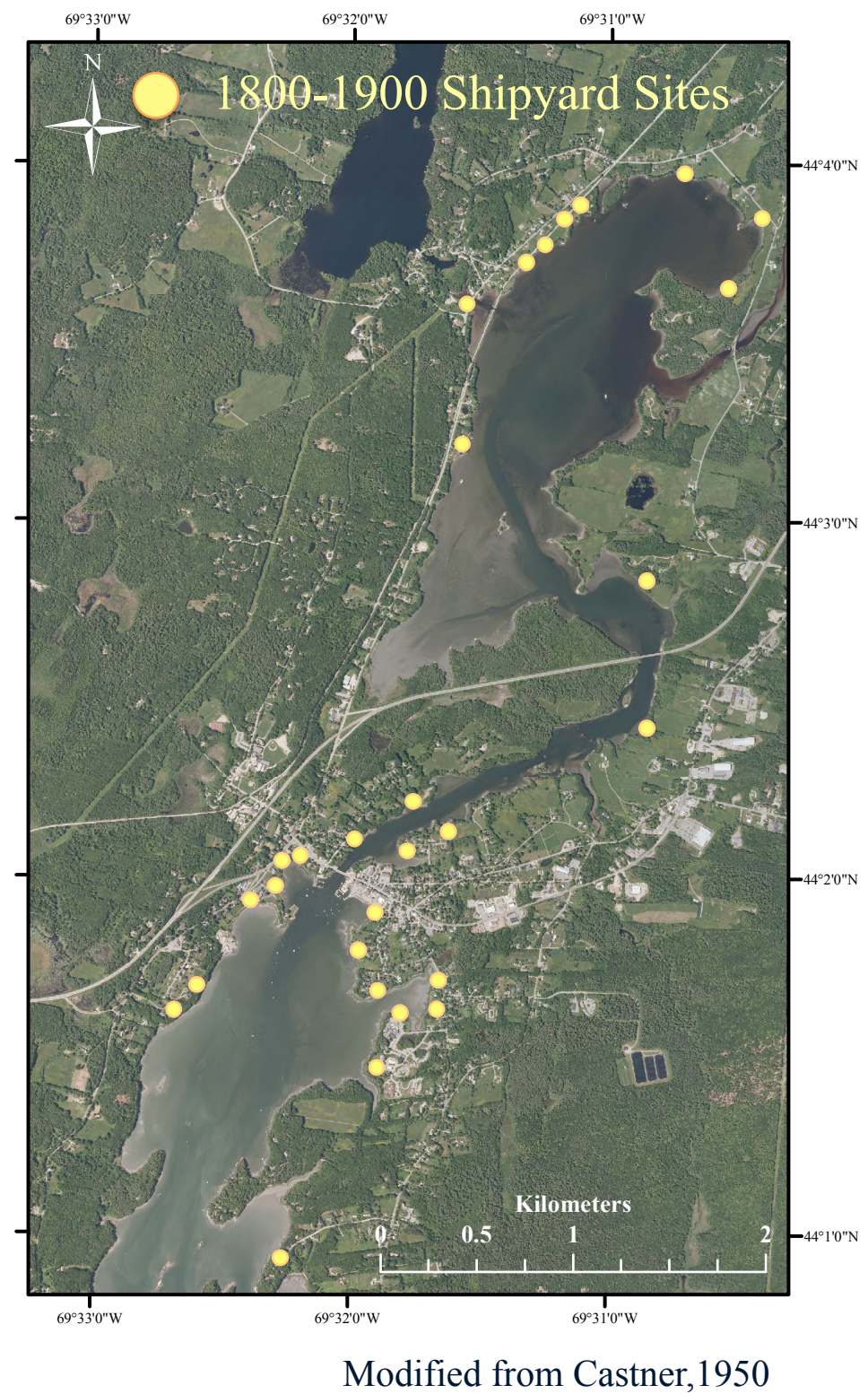




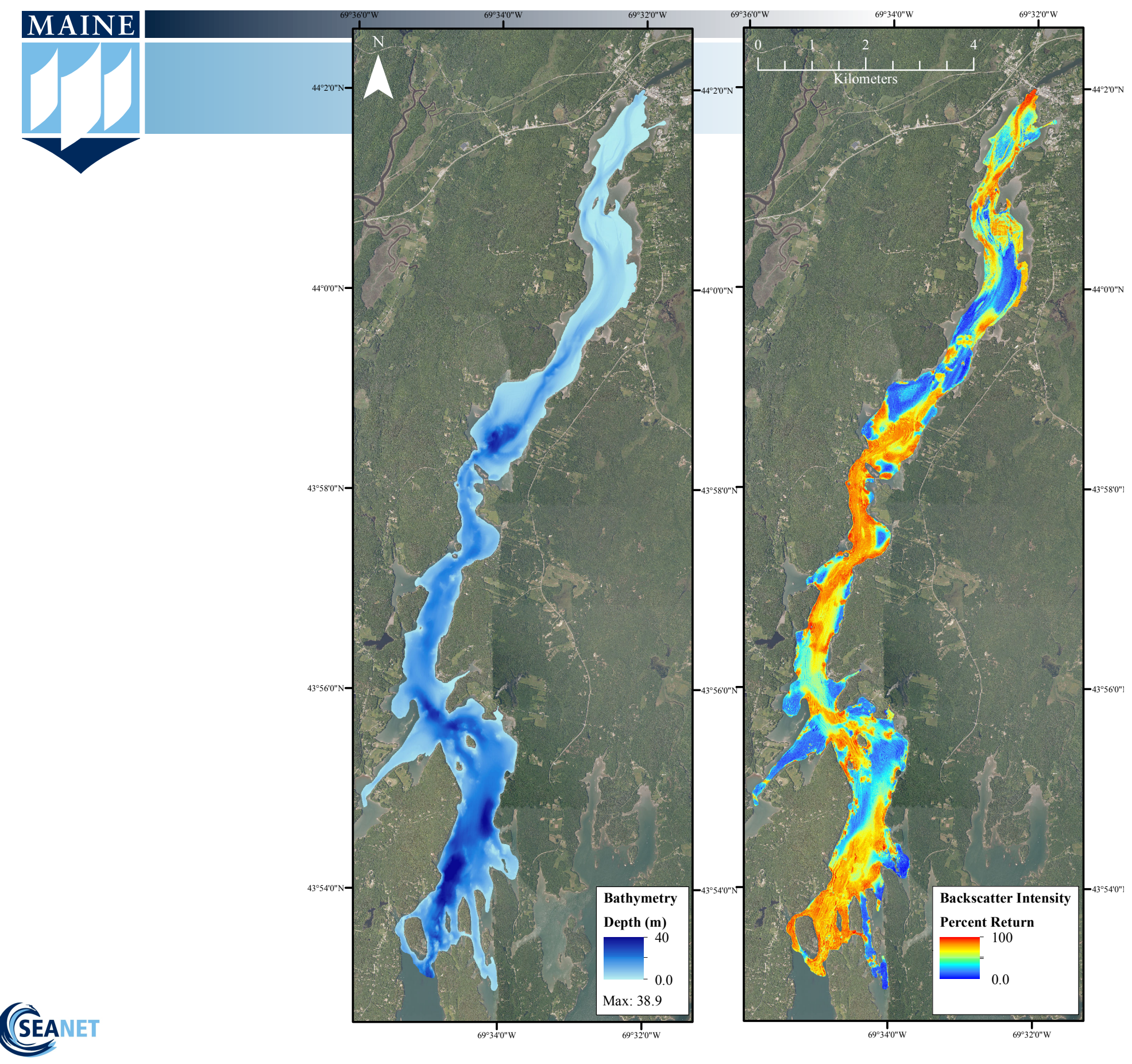




\section{MAINE}

\section{Conclusions}

- New high-resolution bathymetry \& surficial sediment distribution.

- Zones of low sediment accumulation, extensive reworking, erosion.

- Sediment distribution related to bedrock framework \& tides.

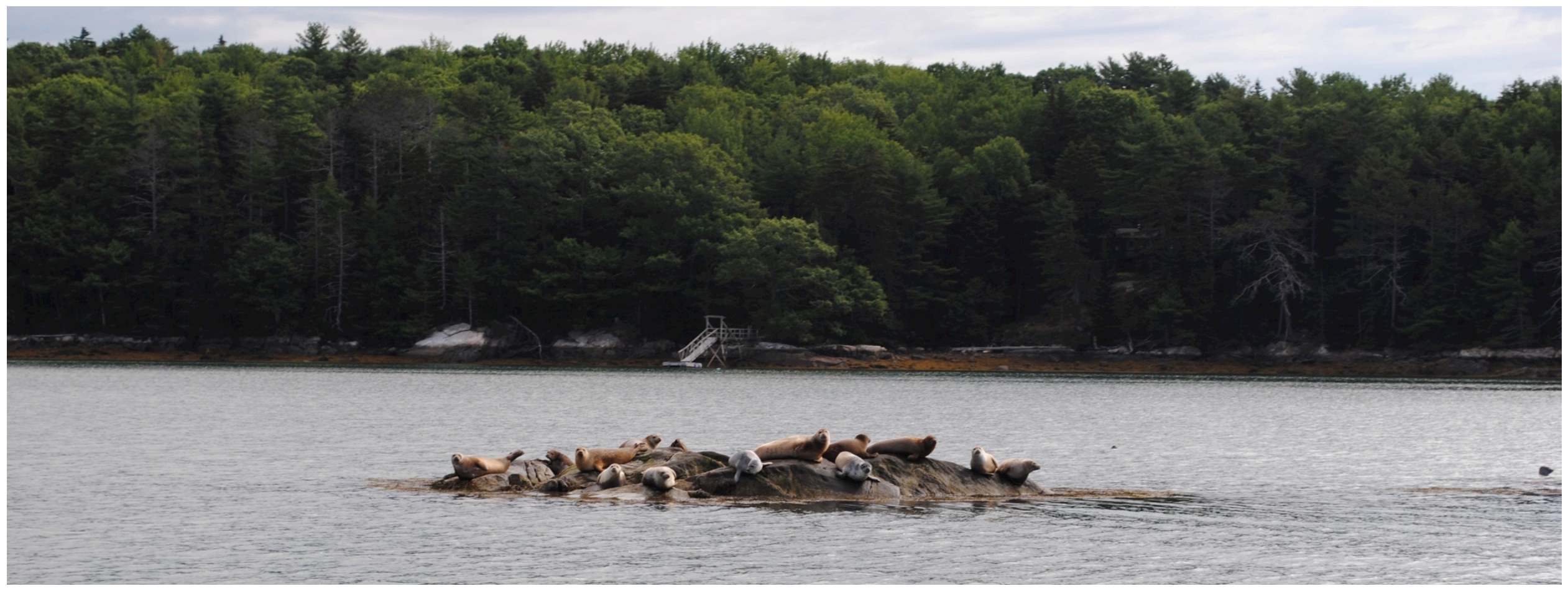




\section{MAINE}

\section{Acknowledgements}

Dr. Joseph T. Kelley

Dr. Daniel F. Belknap

Dr. Lawrence M. Mayer

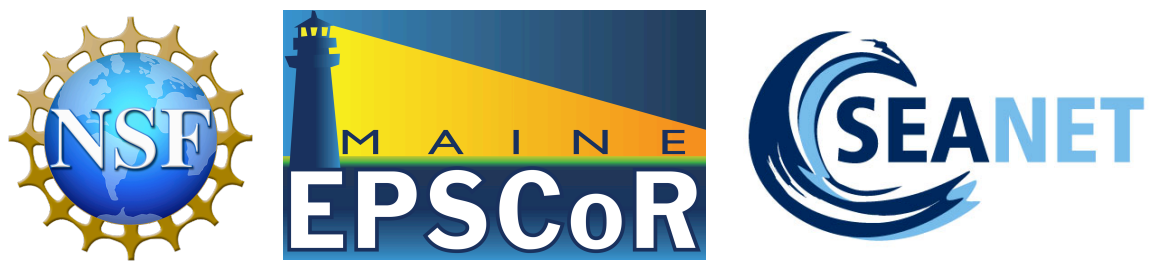

Maine EPSCoR SEANET Award: IIA-1355457

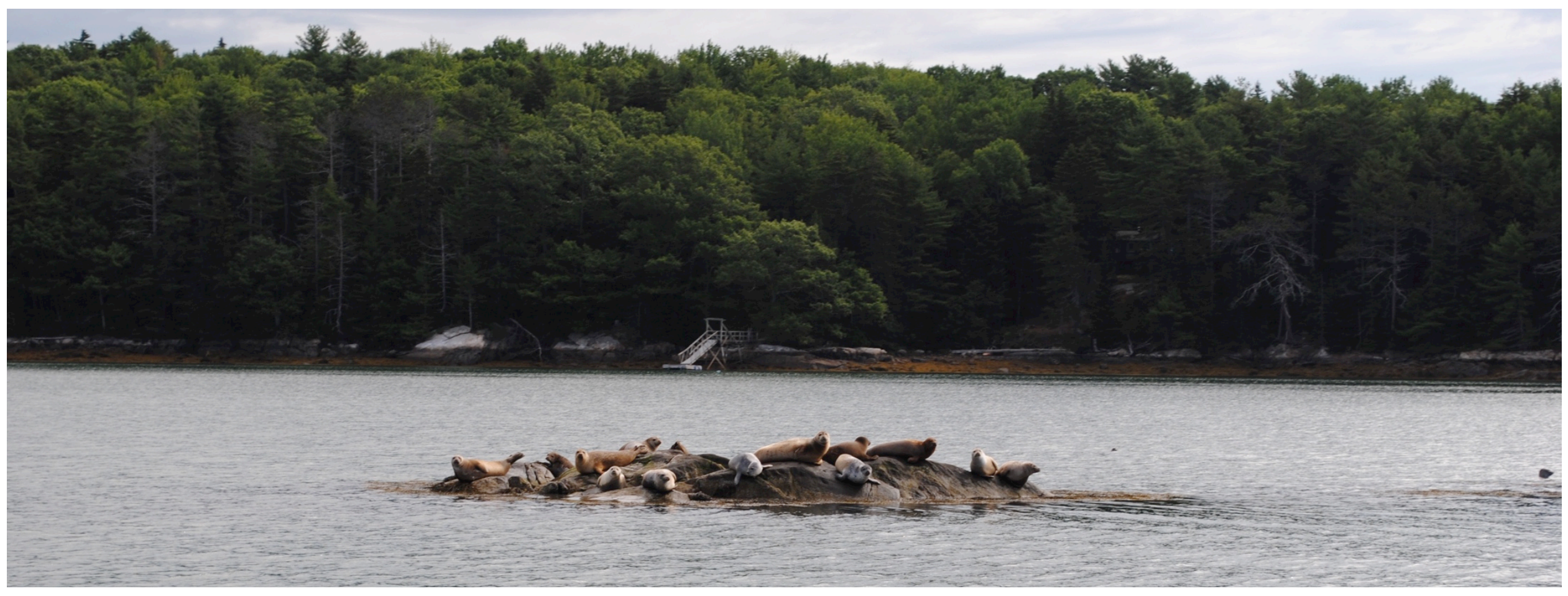

Long Cove, Damariscotta River: DR-PC-15-02, Core 2, Site 